\title{
Frequent Genital Herpes Simplex Virus 2 Shedding in Immunocompetent Women Effect of Acyclovir Treatment
}

\author{
Anna Wald, ${ }^{\star}$ Lawrence Corey, ${ }^{\star \ddagger}$ Richard Cone, ${ }^{\ddagger}$ Ann Hobson, ${ }^{\ddagger}$ Gray Davis,, and Judy Zeh ${ }^{\S}$ \\ $*$ Department of Medicine, ${ }^{\ddagger}$ Department of Laboratory Medicine, and ${ }^{\S}$ Department of Statistics, University of Washington, Seattle, \\ Washington 98195; and the "Glaxo Wellcome Company, Research Triangle Park, Durham, North Carolina 27709
}

\begin{abstract}
Reactivation of herpes simplex virus type 2 (HSV-2) occurs intermittently as perceived clinically and by viral culture. We performed a series of studies to evaluate the frequency and pattern of HSV-2 reactivation using both viral isolation and HSV PCR assay. Daily samples of genital secretions were obtained from $27 \mathrm{HSV}-2$ seropositive women; a subset of subjects obtained samples while receiving oral acyclovir $400 \mathrm{mg}$ PO twice a day. HSV DNA was detected in genital swab specimens on $28 \%$ of $1,410 \mathrm{~d}$ compared with $8.1 \%$ of days by viral isolation. 11 of 20 women had HSV DNA detected on $>20 \%$ of days, 4 on $>50 \%$, and 2 on $>75 \%$ of days; in contrast, none of the women shed on $>21 \%$ of days by viral isolation. The daily administration of oral acyclovir promptly reduced the frequency of HSV DNA detection by a median of $80 \%$. Within 3-4 d of discontinuing daily acyclovir, HSV DNA again appeared in the genital area. HSV-2 shedding in the genital mucosa occurs much more frequently than previously appreciated. This frequent reactivation likely plays a role in the epidemic spread of genital herpes worldwide. (J. Clin. Invest. 1997. 99:1092-1097.) Key words: herpes genitalis $\cdot$ herpes simplex $\bullet$ polymerase chain reaction $\cdot$ acyclovir $\cdot$ viral sexually transmitted diseases
\end{abstract}

\section{Introduction}

Herpes simplex viruses (HSV) ${ }^{1}$ are ubiquitous human pathogens (1). Herpes simplex virus type 2 (HSV-2) is the major cause of genital herpes and one of the most frequent sexually transmitted diseases (STDs) worldwide. In industrialized countries HSV-2 is the leading cause of genital ulcer disease and an independent risk factor for the acquisition of HIV infection $(2,3)$. Recent serosurveys of adults in the United States have shown a $32 \%$ increase in the prevalence of HSV-2 be-

Dr. Cone's current address is Division of Infectious Diseases, Department of Internal Medicine, University Hospital, Zurich, Switzerland, CH8091.

Address correspondence to Anna Wald, M.D., M.P.H., Acting Assistant Professor, University of Washington, Virology Research Clinic, 1001 Broadway, Suite 320, Seattle, WA 98122. Phone: 206720-4340; FAX: 206-720-4371; E-mail: annawald@u.washington.edu

Received for publication 29 July 1996 and accepted in revised form 19 December 1996.

1. Abbreviations used in this paper: HSV, herpes simplex virus; HSV-2, herpes simplex virus type 2 .

J. Clin. Invest.

(C) The American Society for Clinical Investigation, Inc. 0021-9738/97/03/1092/06 \$2.00

Volume 99, Number 5, March 1997, 1092-1097 tween 1978 and 1990 (4; Johnson, R., personal communication). The pathogenesis of HSV infection involves acute infection, subsequent latency in neuronal cells, and intermittent reactivation of virus with reinfection of epithelial cells and spread of virus on mucosal surfaces $(5,6)$. Among persons with clinical genital herpes, symptomatic reactivations of genital herpes occur from 4 to 15 times/yr (median 5/yr), genital lesions last from 3 to $12 \mathrm{~d}$ (median 7), and HSV can be isolated from the lesions for 1 to $4 \mathrm{~d}$ (7-9). Subclinical shedding of the virus in the genital tract has been estimated to occur on $1-4 \%$ of days sampled (10-15). This intermittent reactivation of HSV has led to a management strategy that emphasizes episodic therapy of symptomatic reactivation, and counseling of patients with genital herpes about the potential of transmitting infection to sexual partners during clinical recurrences (16).

HSV DNA detection by PCR has been shown to be more sensitive than viral isolation for detection of HSV in cerebrospinal fluid and in genital lesions (17-19). In initial studies evaluating the use of PCR for detecting subclinical shedding of HSV in genital secretions at the onset of birth labor, we noted a much higher frequency of HSV by PCR than by viral isolation (20). To evaluate whether this was unique to pregnancy, we initiated two studies to evaluate the frequency of HSV-2 reactivation in the genital tract: an initial pilot trial to estimate the frequency of subclinical reactivation in the genital tract, and a second crossover treatment trial to evaluate whether antiviral therapy which inhibits viral replication could abrogate the detection of PCR positivity.

\section{Methods}

Subjects and clinical procedures. Studies were conducted at the University of Washington Virology Research Clinic. Subjects were in good health and not receiving immunosuppressive medication; all signed written informed consent. In the pilot study, four women with clinical evidence of genital herpes were followed without antiviral therapy for 40-60 consecutive d. Three of these four women were HSV-2 seropositive (21) and have had HSV-2 isolated from genital lesions. The fourth woman was enrolled on the basis of a recent clinical diagnosis of primary genital herpes. However, HSV was never isolated from her genital tract, nor was HSV DNA detected from the genital area for 46 consecutive $d$. The patient remained seronegative to HSV-1 and HSV-2 by both standard and enhanced chemiluminescent Western blot assays over a 2-yr follow-up period $(21,22)$. She served as a negative control for both the laboratory and specimen collection methods (see Table I, subject 28).

After the pilot trial demonstrated a much higher frequency of HSV DNA detection in genital secretions than viral isolation (see Table I, subjects 1,2, and 27), we evaluated whether HSV shedding as detected by PCR was altered by antiviral chemotherapy. We then studied the first 24 of 34 women who participated in a double-blind, placebo-controlled, crossover study of oral acyclovir 400-mg twice a day to evaluate the effect of antiviral therapy on subclinical shedding of HSV (23). Acyclovir blocks HSV replication by its selective phosphorylation by viral thymidine kinase, and the subsequent interaction 
of acyclovir triphosphate with the HSV DNA polymerase (24). Both of these viral gene products are made relatively late in the viral replication cycle and have never been detected during latent infections (25-27). As such, the in vivo inhibition of PCR positivity by acyclovir would indicate the presence of replicating and hence potentially infectious virus on mucosal surfaces; therefore, we sought to compare detection rates of HSV DNA on and off acyclovir. All women in the acyclovir group were seropositive for HSV-2 only with genital herpes infection for $<2 \mathrm{yr}$, and were sampled daily for $22 \mathrm{wk}$ (23). For the initial $10 \mathrm{wk}$ the subjects received placebo, followed by 2-wk of washout, and $10 \mathrm{wk}$ of acyclovir, or the reverse order. The 2-wk washout period was to assure that the participants will return to baseline rates of reactivation before receipt of the second study drug. Women in the pilot trial and in the study of acyclovir obtained daily swabs of genital secretions for viral isolation and PCR $(13,15,23)$. The cervical specimen was obtained by inserting the swab in the vagina and swabbing the cervix and vaginal fornix. The vulvar specimen was obtained by swabbing the entire vulva. The samples were placed in viral media and stored refrigerated until delivered to the laboratory three times a week. The viral isolation results showed that acyclovir was $94 \%$ effective in reducing subclinical and clinical shedding among these women (23). As the demographic, clinical, and serologic characteristics, and sampling methods of the women as well as the laboratory methods were similar between the two trials, the results of these studies have been combined.
Laboratory methods. Viral isolation, HSV serology by Western blot, and the PCR assay for HSV DNA detection were performed using previously published methods $(21,28,29)$. The samples collected by subjects were opened and divided in a separate P-2 facility. Half of each sample was sent to an adjoining laboratory for HSV isolation using standard tissue culture techniques (28) and half was digested overnight in a buffer containing proteinase $\mathrm{K}$ and sodium dodecyl sulfate, EDTA, and Tris $\mathrm{HCl}, \mathrm{pH}$ 8.0. All HSV isolates were typed by monoclonal antibodies to HSV-2.

DNA was extracted with phenol and phenol chloroform and was then precipitated with ethanol. HSV PCR was performed as previously described (18-20). We used a type common primer set HSVgB2a (5'-CTGGTCAGCTTTCGGTACGA, 5'-CAGGTCGTGCAGCTGGTTGC) from the glycoprotein B gene. A type common probe (HSVgB2a-P: 5'-AGGTCGATGAAGGTGCTGACGGTGGTGA) was used for hybridization with the resulting 342-bp PCR product. To insure negative samples were not due to nonspecific inhibition, all samples were spiked with 50 copies of a modified PCR product containing a 35-bp Drosophila gene sequence replacing the HSV probe region (29). Reactions were then hybridized separately with both the Drosophila probe (to test for inhibition of the reaction) and the HSV probe (to detect HSV DNA in the sample). All inhibited samples ( $\sim 4 \%$ of initial samples) were reextracted and then successfully amplified. All runs also contained uninfected tissue culture negative controls. On selected samples, HSV DNA was subtyped us-

Table I. Frequency of Detection of HSV from Genital Tract of 27 HSV-2 Seropositive Women by Viral Culture and PCR

\begin{tabular}{|c|c|c|c|c|c|c|c|c|c|}
\hline \multirow[b]{2}{*}{$\begin{array}{l}\text { Subject } \\
\text { No. }\end{array}$} & \multirow[b]{2}{*}{$\begin{array}{l}\text { No. days since } \\
\text { HSV acquisitiion }\end{array}$} & \multicolumn{4}{|c|}{ No therapy } & \multicolumn{4}{|c|}{ Daily acyclovir therapy } \\
\hline & & $\begin{array}{l}\text { No. days PCR }+ \text { / } \\
\text { No. days sampled }\end{array}$ & & $\begin{array}{l}\text { No. days culture }+ \\
\text { No. days sampled }\end{array}$ & & $\begin{array}{l}\text { No. days PCR }+/ \\
\text { No. days sampled }\end{array}$ & & $\begin{array}{l}\text { No. days culture }+/ \\
\text { No. days sampled }\end{array}$ & \\
\hline & & & $\%$ & & $\%$ & & $\%$ & & $\%$ \\
\hline 1 & 11 & $20 / 42$ & 47.6 & $5 / 42$ & 11.9 & ND & - & ND & - \\
\hline 2 & 14 & $9 / 56$ & 16.1 & $0 / 56$ & 0.0 & ND & - & ND & - \\
\hline 3 & 76 & $11 / 65$ & 16.9 & $5 / 65$ & 7.7 & ND & - & ND & - \\
\hline 4 & 95 & ND & - & ND & - & $1 / 53$ & 1.9 & $1 / 53$ & 1.9 \\
\hline 5 & 99 & ND & - & ND & - & $1 / 74$ & 1.4 & $0 / 74$ & 0.0 \\
\hline 6 & 113 & $59 / 77$ & 76.6 & $15 / 77$ & 19.5 & $8 / 64$ & 12.5 & $0 / 64$ & 0.0 \\
\hline 7 & 147 & $45 / 80$ & 56.3 & $17 / 80$ & 21.3 & $13 / 69$ & 18.8 & $0 / 69$ & 0.0 \\
\hline 8 & 153 & ND & - & ND & - & $12 / 72$ & 16.7 & $0 / 72$ & 0.0 \\
\hline 9 & 153 & ND & - & ND & - & $1 / 64$ & 1.6 & $0 / 64$ & 0.0 \\
\hline 10 & 155 & $7 / 69$ & 10.1 & $1 / 69$ & 1.4 & ND & - & ND & - \\
\hline 11 & 159 & $27 / 85$ & 31.8 & $5 / 85$ & 5.9 & $2 / 64$ & 3.1 & $0 / 64$ & 0.0 \\
\hline 12 & 174 & $19 / 80$ & 23.8 & $4 / 80$ & 5.0 & 7/72 & 9.7 & $0 / 72$ & 0.0 \\
\hline 13 & 181 & $34 / 44$ & 77.3 & $8 / 44$ & 18.2 & $13 / 69$ & 18.8 & $1 / 69$ & 1.4 \\
\hline 14 & 243 & $41 / 81$ & 50.6 & $12 / 81$ & 14.8 & 7/71 & 9.9 & $0 / 71$ & 0.0 \\
\hline 15 & 336 & $25 / 78$ & 32.1 & $5 / 78$ & 6.4 & $2 / 67$ & 3.0 & $1 / 67$ & 1.5 \\
\hline 16 & 400 & $6 / 63$ & 9.5 & $0 / 63$ & 0.0 & ND & - & ND & - \\
\hline 17 & 447 & ND & - & ND & - & $1 / 66$ & 1.5 & $0 / 66$ & 0.0 \\
\hline 18 & 500 & $25 / 80$ & 31.3 & $12 / 80$ & 15.0 & $2 / 65$ & 3.1 & $0 / 65$ & 0.0 \\
\hline 19 & 501 & $10 / 82$ & 12.2 & $0 / 82$ & 0.0 & $6 / 74$ & 8.1 & $0 / 74$ & 0.0 \\
\hline 20 & 540 & $14 / 77$ & 18.2 & $2 / 77$ & 2.6 & ND & - & ND & - \\
\hline 21 & 564 & ND & - & ND & - & $6 / 55$ & 10.9 & $1 / 55$ & 1.8 \\
\hline 22 & 607 & $17 / 71$ & 23.9 & $12 / 71$ & 16.9 & ND & - & ND & - \\
\hline 23 & 618 & $6 / 82$ & 7.3 & $0 / 82$ & 0.0 & ND & - & ND & - \\
\hline 24 & 643 & ND & - & ND & - & $3 / 65$ & 4.6 & $0 / 65$ & 0.0 \\
\hline 25 & 714 & $0 / 76$ & 0.0 & $0 / 76$ & 0.0 & ND & - & ND & - \\
\hline 26 & 717 & $4 / 63$ & 6.3 & $2 / 63$ & 3.2 & ND & - & ND & - \\
\hline 27 & 2247 & $15 / 59$ & 25.4 & $9 / 59$ & 15.3 & ND & - & ND & - \\
\hline Total & & $394 / 1410$ & 27.9 & $114 / 1410$ & 8.1 & $85 / 1064$ & 8.0 & $4 / 1064$ & 0.4 \\
\hline 28 & No HSV & $0 / 46$ & 0.0 & $0 / 46$ & 0.0 & ND & - & ND & - \\
\hline
\end{tabular}


ing HSV-1 and HSV-2 type-specific probes (20). We quantitated the approximate number of HSV genomic copies in swab specimens by comparing the intensity of the band on the autoradiogram in $50 \mu \mathrm{l}$ of specimen with bands generated from input HSV DNA of known copy number $\left(10^{1}\right.$ to $\left.10^{4}\right)$. Previous studies had shown that the intensity of the bands linearly increased up to $10^{4}$ copies of HSV DNA; all samples in which initial testing revealed $>10^{3}$ copies of HSV DNA/50 $\mu \mathrm{l}$ of sample were diluted to give copy numbers in the range of $10^{1}$ to $10^{4}$ and reamplified using this method. We visually estimated on a $\log$ scale the amount of HSV DNA in each specimen. This method gives results which are comparable to results obtained by quantitative competitive HSV DNA PCR (30). The PCR, viral isolation, and serologic assays were all done without knowledge of clinical or culture results.

To examine how long inactivated HSV DNA would persist on the mucosa of the genital tract in the absence of replicating virus, we placed $10^{6}$ plaque forming units of heat-inactivated HSV-1 (strain E115) on the external genitalia of a seronegative woman. High levels of HSV DNA $\left(10^{6}\right.$ genome copies $/ 50 \mu$ of sample) were detected on the vulva immediately after placement. The amount of HSV DNA decreased rapidly by $5 \mathrm{~h}$ after the placement of HSV, and none was detected by $24 \mathrm{~h}$ after placement.

Definitions and statistical methods. Subclinical shedding was defined as the detection of HSV on a day without genital lesions noted by the patient or clinician (15). The frequency of HSV shedding was calculated by dividing the number of days on which HSV was isolated or detected by PCR by the number of days of samples. Previous studies have shown the similarity in the rate of viral isolation among patient-obtained specimens versus clinician-obtained cultures (15). To evaluate the reliability of patients sampling methods by PCR, we compared results on $140 \mathrm{~d}$ on which vulvar and cervical samples were obtained on the same day both at home and in the clinic. Of these 280 home-clinic sample pairs, 202 were negative. Of 78 pairs with HSV DNA, $55(71 \%)$ were positive from swabs taken both at home and the clinic, $13(17 \%)$ were positive only in samples obtained at home, while $10(13 \%)$ were positive only in samples obtained at clinic $(\kappa=$ $0.77,95 \%$ confidence interval $0.69-0.86$ ). Among the 55 pairs with DNA in both home and clinic samples, $24(44 \%)$ had the same amount of HSV DNA detected in both samples, 26 (47\%) pairs had a 1 or $2 \log$ difference and only $5(9 \%)$ had a $3 \log$ difference in HSV DNA between the two samples. Thus the patient sampling method for detecting HSV DNA from mucosal surfaces appeared reliable.

We calculated geometric means of numbers of genomic copies in samples, with PCR-negative samples assigned the value $10^{\circ}=1$. Because the test results within a woman are correlated, we computed summary statistics for each woman, and significance tests were done using these summary statistics. Correlation coefficients were Pearson correlations, with significance assessed by the $F$ test from a least squares regression. Comparisons of mean amounts of HSV DNA under different conditions (untreated versus acyclovir, culture positive vs. culture negative, lesions present versus not) were done using paired two-sided $t$ tests $(\alpha=0.05)$ on the women with data under both conditions. The average from the cervical and vulvar samples for each woman under each condition was computed on the log scale for these tests.

\section{Results}

We assayed each of the daily genital tract specimens on 20 HSV-2 seropositive women who were not receiving antiviral therapy. HSV DNA was detected in genital secretions in 19 (95\%) women during 42 to 85 consecutive sampling days, and HSV was isolated by culture in 15 (75\%) women (Table I). Overall, HSV DNA was detected on 394 of $1,410(28 \%)$ of days sampled, compared to $114 \mathrm{~d}(8.1 \%)$ on which HSV was isolated by culture from the same specimens (Fig. 1). The median percent of days on which HSV DNA was detected in the vulvar or cervical areas was $24 \%$ and ranged from zero in one woman (subject 25 ) to $>75 \%$ of days in two subjects (subjects 6 and 13). The frequency of HSV DNA detection in cervical and vulvar samples was similar, 23 and $24 \%$ of days, respectively. HSV DNA was detected in all but one sample from which HSV was isolated. In individual women, the correlation between HSV-culture positivity and HSV DNA detection was $0.83(P<0.001)$; that is, women with frequent detection of HSV DNA had frequent HSV detection by standard viral isolation. In agreement with previous studies in which only viral isolation was performed $(14,15)$, detection of HSV DNA was higher in women enrolled into the study within 6 mo of acquiring HSV-2 than those between 6 and 24 mo, 39\% vs. 20\% of days, respectively (Table I).

The appearance of HSV DNA occurred in clusters of consecutive days, or episodes, similar to the pattern previously seen in studies evaluating HSV reactivation by viral isolation (Fig. 2). Overall, the median duration of an episode of HSV shedding as detected by PCR was $2 \mathrm{~d}$ (range 1 to 34). Of 107 episodes, 45 (42\%) lasted $1 \mathrm{~d}, 20(19 \%) 2 \mathrm{~d}, 8$ (7\%) $3 \mathrm{~d}, 5$ (5\%) $4 \mathrm{~d}$, and $29(27 \%) 5 \mathrm{~d}$ or more. Lesions consistent with herpes were noted on $40 \%$ of days on which HSV DNA was detected. The median duration of PCR positivity during lesional episodes was $4 \mathrm{~d}$ vs. $1 \mathrm{~d}$ for subclinical episodes.

Amount of HSV DNA in genital secretions. Among the 663 cervical and vulvar specimens in which HSV DNA was detected, the number of genomic copies per $50 \mu \mathrm{l}$ of specimen was $\sim 10^{1}$ in $36 \%, 10^{2}$ in $19 \%, 10^{3}$ in $15 \%, 10^{4}$ in $13 \%, 10^{5}$ in $5 \%, 10^{6}$ in $5 \%$, and $10^{7}$ or more in $6 \%$. The distribution of the amount of DNA was similar in vulvar and cervical specimens. The estimated HSV copy number was significantly higher in PCR-positive samples from which HSV-2 was isolated (mean difference $10^{2.00}, 95 \%$ CI $10^{1.49}$ to $10^{2.51}, P<0.001$ ); $72 \%$ of culture-positive vulvar samples contained $>10^{3}$ copies of HSV DNA and only one culture-positive sample was PCR-negative. Nevertheless, $19 \%$ of PCR-positive, culture-negative vulvar specimens had more than $10^{3}$ copies of HSV DNA and $7 \%$ had more than $10^{5}$ copies. Moreover, HSV was isolated on days in which only low (10 or 100) copies of HSV DNA were detected
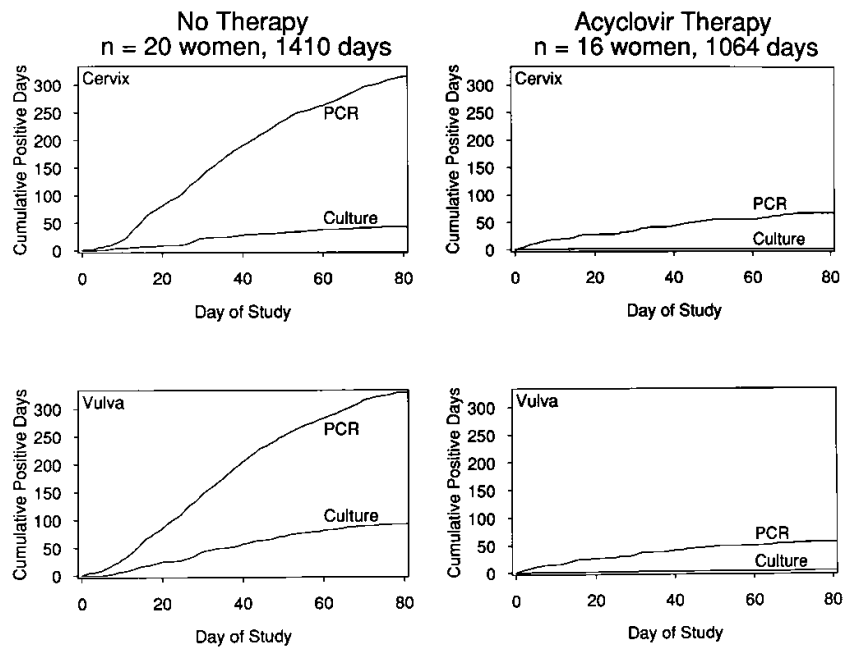

Figure 1. The cumulative culture and PCR-positive days from samples of genital secretions from women on placebo or acyclovir therapy. The cumulative number of days is illustrated both for the cervix and for the vulva. 


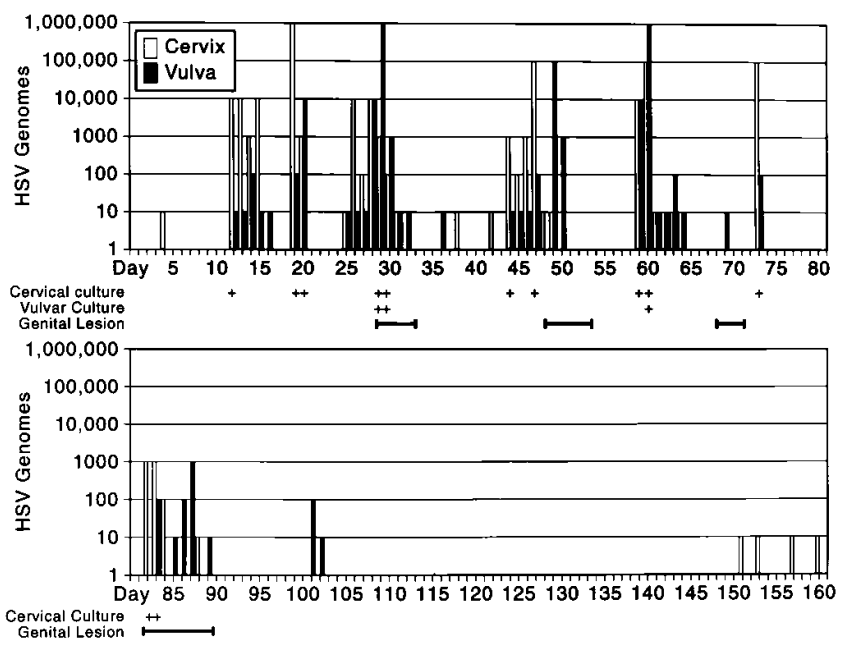

Figure 2. The virologic and clinical course of HSV infection of subject 14 during placebo and acyclovir therapy. The + denotes a day in which HSV was isolated by culture; on all other days HSV cultures revealed no growth. The woman received placebo on day 1-88 of study and acyclovir 400-mg twice a day on days 89-160. Day, consecutive day of sampling.

(Fig. 3). The geometric mean HSV copy number was significantly higher in samples obtained on days with lesions than days without lesions, $10^{1.74}$ and $10^{0.44}(P<0.001)$, respectively (see days 29-33 and 48-53 in Fig. 2). Of interest, on the days with positive cultures, the presence or absence of genital lesions did not appreciably alter the amount of HSV DNA present $-10^{4.43}$ for days with genital lesions compared with $10^{4.04}$ for days without lesions.

Effect of acyclovir on detection of HSV DNA. In 16 women receiving daily suppressive acyclovir, we evaluated the frequency and amount of HSV DNA on mucosal surfaces. Daily oral acyclovir markedly reduced the frequency of HSV DNA detection (Table I, Figs. 1 and 2). Overall, HSV reactivation as measured by DNA detection in genital swabs was reduced from 394 of $1,410 \mathrm{~d}(28 \%)$ during untreated period to 85 of $1,064 \mathrm{~d}(8 \%)$ during acyclovir therapy. Among the nine women who obtained specimens both on placebo and on acyclovir, the frequency with which HSV DNA was detected by

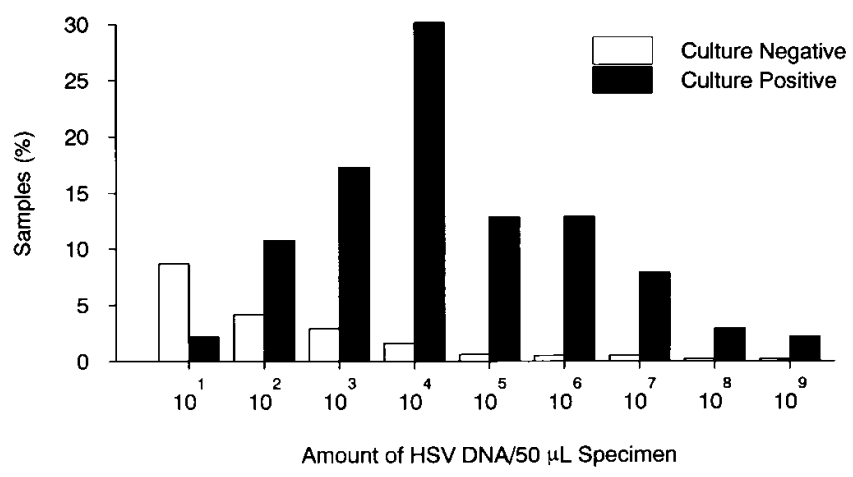

Figure 3. The distribution of the amount of HSV DNA/50 $\mu$ l of specimen obtained from cervical and vulvar swabs on days HSV was isolated in culture compared to days HSV was not isolated from women not receiving antiviral therapy.

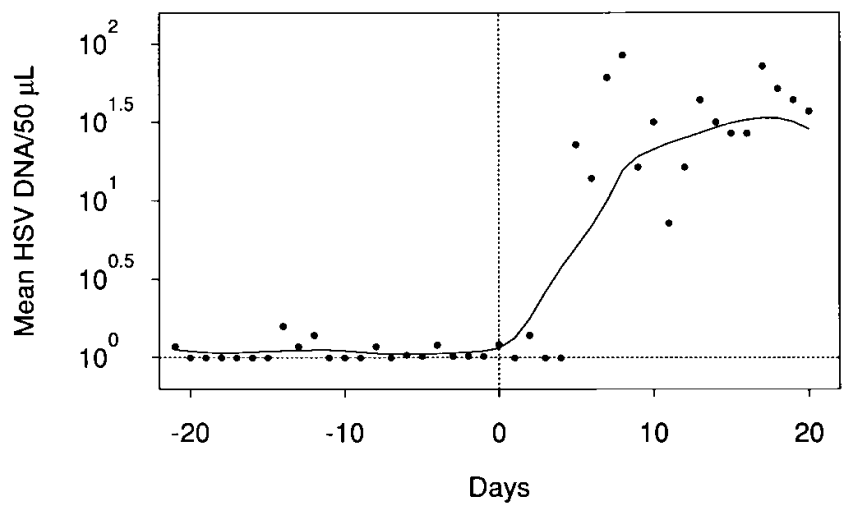

Figure 4. Temporal association between discontinuation of daily oral acyclovir and the ability to detect HSV DNA in genital swabs. End point is the daily mean copy number of HSV DNA in the 3 wk before and $3 \mathrm{wk}$ immediately after discontinuing oral acyclovir 400-mg PO twice a day $(n=7)$. The line depicts a locally weighted smoothed version of the daily data.

PCR was reduced from 285 of 687 d (41\%) to 60 of $615 \mathrm{~d}$ (10\%); a median reduction of $80 \%$ (range 34-91\%). Additionally, women who had high rates of shedding by PCR without antiviral therapy tended to have higher shedding rates on acyclovir as well $(r=0.7, P=.03)$.

HSV DNA detection markedly decreased upon the initiation of acyclovir and promptly increased within $4 \mathrm{~d}$ of stopping acyclovir. Mean HSV DNA was reduced from baseline (no treatment) levels of $10^{1.06}$ to $10^{0.72}$ on days $1-3$ of acyclovir therapy, $10^{0.37}$ on days $4-6$, and to $10^{0.09}$ on days $\geq 7$ of therapy. Similarly, the reemergence of PCR positivity was prompt when acyclovir was discontinued (Fig. 4). When HSV DNA was detected in the genital tract, the number of HSV genomic copies was significantly reduced from $10^{2.75}$ on placebo to $10^{1.62}$ on acyclovir (mean difference $10^{1.12}, 95 \%$ CI $10^{0.26}$ to $10^{1.99}, P=$ 0.02). The reduction of detection of HSV DNA in genital tract was seen in all women and at both anatomic sites during acyclovir administration.

\section{Discussion}

Our study indicates that genital HSV-2 reactivation occurs much more commonly than previously appreciated. Using a sensitive HSV DNA PCR assay, we found HSV-2 shedding in the cervico-vaginal or vulvar region an average of $28 \%$ of days sampled among healthy immunocompetent HSV-2 seropositive women. The rate of HSV detection by PCR was 3.5 times higher than viral isolation when the same specimens were evaluated by both methods. Both the epidemiologic and virologic pattern of HSV reactivation as detected by PCR paralleled the known characteristics of mucosal HSV-2 infection as shown previously by viral isolation (15). HSV reactivation as detected by PCR: (a) was more frequent in women with recent acquisition of genital herpes and frequent reactivation by viral isolation; (b) occurred in clusters of days or episodes; (c) was associated with higher copy numbers and longer duration of shedding when viral cultures were positive or genital lesions were present; and (d) was reduced with antiviral therapy. These data all support the conclusion that detection of HSV DNA on a genital mucosal swab indicates recent replication and release of virus 
from mucosal epithelial cells. This conclusion is supported by our preliminary observation which demonstrated that high copy number of heat inactivated HSV DNA rapidly disappeared from mucosal surfaces. The HSV PCR assay which we used has been extensively evaluated for specificity in prior studies (18-20); and genital samples from HSV seronegative persons were invariably negative, as demonstrated by subject 28 in Table I.

The marked reduction in HSV DNA detection which occurred on daily acyclovir provides evidence that most of the HSV DNA in genital swabs is replicating rather than latent or defective virus. No evidence of latent HSV has been found in human genital tract, despite findings of latent or low frequency replicating HSV in the guinea pig, mouse mucosa, or the human cornea (31-33). For activity, acyclovir requires HSV-specified enzymes which are not produced during latent infection (24-27). As such, suppression of HSV DNA detection with acyclovir therapy would indicate that we detect replicating virus on the mucosal surface. The prompt reduction of PCR positivity after initiation of acyclovir and the rapid reappearance of HSV DNA positivity upon discontinuing acyclovir also support this observation. The median reduction in shedding during acyclovir therapy was $100 \%$ by viral isolation compared with $80 \%$ by PCR assay; it is not clear whether the low-level HSV DNA which remained detectable during antiviral therapy represented infectious virus. However, as shown in Fig. 3, HSV-2 can be isolated in tissue culture when only 10 to 100 copies of HSV DNA are detected in concomitantly obtained genital swabs.

Our study leaves several important issues yet unanswered. Despite the large number of samples in this study $(>8,000$ PCR assays), the number of persons we studied was small. Our goal was to investigate if HSV reactivated more frequently than previously appreciated by viral culture, not to define the entire clinical spectrum of such reactivations. As such, additional information on HSV shedding patterns in a wider variety of patient populations is needed. The estimates of subclinical shedding that we report in this paper may be low, as we sampled only the vulvar and cervical areas. As detected by viral isolation in previous studies (15), perianal shedding is common in both women and heterosexual men and results from innervation of the region by the sacral nerves.

Clinical implications. Our findings have several clinical implications. Persons with HSV-2 infection need to be more actively counseled about the frequency of subclinical reactivation in the genital tract. They should be informed that HSV-2 shedding on mucosal surfaces occurs frequently and, as such, exposure to potentially infectious virus does not occur on just $2 \%$ of days (15). One interesting finding of our study was that the amount of HSV DNA that we detected in genital secretions was similar in subclinical or lesional culture positive episodes of HSV-2. We have assayed culture negative genital secretions from two women at the time of delivery whose infants subsequently developed neonatal HSV (20). HSV DNA was detected in samples from both women, and the genomic copies varied from $10^{3}$ to $10^{5}$. These data indicate that HSV-2 can be transmitted when HSV DNA is detected by PCR but HSV is not isolated in culture. High copy number of HSV DNA correlated with our ability to isolate virus, and is likely to be a factor in transmissibility of infection. However, other factors influence sexual transmission of HSV-2 infection, such as antibody titers of the exposed sexual partner and the type and duration of coital activity. Thus, it may not be possible to establish the threshold level of HSV DNA which results in transmissible infection. As such, consistent use of barriers to prevent transmission of genital herpes should be a routine message for all persons at risk for transmitting HSV to others.

In summary, while the pathogenic mechanisms of HSV-2 shedding on mucosal surfaces are incompletely understood, models of HSV intervention, whether behavioral or chemotherapeutic, need to take into account the very frequent release of replicating herpes simplex virions into mucosal surfaces.

\section{Acknowledgments}

The authors thank the women who participated in the study, Gail Barnum, the study coordinator, for her clinical expertise, and Mark Urnes and Nancy Wright for excellent technical assistance.

Supported by National Institutes of Health Grant AI-30731. A. Wald is the recipient of a 1994-1996 American Social Health Association Postdoctoral Research Fellowship in Sexually Transmitted Diseases.

\section{References}

1. Corey, L., and P.G. Spear. 1986. Infections with herpes simplex viruses. N. Engl. J. Med. 314:686-691, 749-757.

2. Stamm, W.E., H.H. Handsfield, A.M. Rompalo, R.L. Ashley, P.L. Roberts, and L. Corey. 1988. Association between genital ulcer disease and acquisition of HIV infection in homosexual men. J. Am. Med. Assoc. 260:1429-1433.

3. Hook, E.W. III, R.O. Cannon, A.J. Nahmias, F.F. Lee, C.H. Campbell, D. Glasser, and T.C. Quinn. 1992. Herpes simplex virus infection as a risk factor for HIV infection in heterosexuals. J. Infect. Dis. 165:251-255.

4. Johnson, R.E. A.J. Nahmias, L.S. Magdar, F.K. Lee, C.A. Brooks, and C.B. Snowden. 1990. A seroepidemiologic survey of the prevalence of herpes simplex virus type 2 infection in the United States. N. Engl. J. Med. 321:7-12.

5. Baringer, J.R. 1974. Recovery of herpes simplex virus from human sacral ganglions. N. Engl. J. Med. 291:828-830.

6. Stanberry, L.R. 1992. Pathogenesis of herpes simplex virus infections and animal models for its study. Curr. Top. Microbiol. Immunol. 179:15-30.

7. Benedetti, J., L. Corey, and R. Ashley. 1994. Recurrence rates of genital herpes after acquisition of symptomatic first episode infection. Ann. Intern. Med. 121:847-854.

8. Corey, L., H.G. Adams, Z.A. Brown, and K.K. Holmes. 1983. Genital herpes simplex virus infection: clinical manifestations, course and complications. Ann. Intern. Med. 98:958-972.

9. Sacks, S.L., L.D. Tyrrell, D. Lawee, W. Schlech, M.J. Gill, F.Y. Aoki, A.Y. Martel, J. Singer, and the Canadian Cooperative Study Group. 1991. Randomized, double-blind, placebo-controlled, clinic-initiated, Canadian multicenter trial of topical Edoxudine 3.0\% cream in the treatment of recurrent genital herpes. J. Infect. Dis. 164:665-672.

10. Rattray, M.C., L. Corey, W.C. Reeves, L.A. Vontver, and K.K. Holmes 1978. Recurrent genital herpes among women: symptomatic vs asymptomatic viral shedding. Br. J. Vener. Dis. 54:262-265.

11. Adam, E., G.E. Dreesman, R.H. Kaufman, and J. L. Melnick. 1981. Asymptomatic virus shedding after herpes genitalis. Am. J. Obstet. Gynecol. 137:827-830.

12. Barton, S.E., J.M. Davis, V.W. Moss, A. S. Tyms, and P.E. Munday. 1987. Asymptomatic shedding and subsequent transmission of genital herpes simplex virus. Genitourin. Med. 63:102-105.

13. Brock, B.V., S. Selke, J. Benedetti, J.M. Douglas, and L. Corey. 1990. Frequency of asymptomatic shedding of HSV in women with genital herpes. $J$. Amer. Med. Assoc. 263:418-420.

14. Koelle, D.M., J. Benedetti, A. Langenberg, and L. Corey. 1992. Asymptomatic reactivation of herpes simplex virus in women after the first episode of genital herpes. Ann. Intern. Med. 116:433-437.

15. Wald, A., J. Zeh, S. Selke, R.L. Ashley, and L. Corey. 1995. Virologic characteristics of subclinical and symptomatic genital herpes infections. $N$. Engl. J. Med. 333:770-775.

16. Centers for Disease Control and Prevention. 1993. Sexually transmitted diseases treatment guidelines. Morb. Mortal. Wkly. Rep. 42:22-25.

17. Lakeman, F.D., and R.J. Whitley. 1995. Diagnosis of herpes simplex encephalitis; application of polymerase chain reaction to cerebrospinal fluid from brain-biopsied patients and correlation with disease. J. Infect. Dis. 171:857-863.

18. Cone, R.W., A.C. Hobson, J. Palmer, M. Remington, and L. Corey. 1991. Extended duration of herpes simplex virus DNA in genital lesions de- 
tected by polymerase chain reaction. J. Infect. Dis. 164:757-760.

19. Cone, R.W., P.D. Swenson, A.C. Hobson, M. Remington, and L. Corey. 1993. Herpes simplex virus detection from genital lesions: a comparative study using antigen detection (HerpChek) and culture. J. Clin. Microbiol. 31:17741776 .

20. Cone, R.W., A.C. Hobson, Z. Brown, R. Ashley, S. Berry, C. Winter, and L. Corey. 1994. Frequent detection of genital herpes simplex virus DNA by polymerase chain reaction among pregnant women. J. Am. Med. Assoc. 272: $792-796$

21. Ashley, R.L., J. Militoni, F. Lee, A. Nahmias, and L. Corey. 1988. Comparison of western blot (immunoblot) and G-specific immunodot enzyme assay for detecting antibodies to herpes simplex virus types 1 and 2 in human sera. $J$. Clin. Microbiol. 26:662-667.

22. Dalessio, J., and R. Ashley. 1992. Highly sensitive enhanced chemiluminescence immunodetection method for herpes simplex virus type 2 western immunoblot. J. Clin. Microbiol. 30:1005-1007.

23. Wald, A., J. Zeh, G. Barnum, L.G. Davis, and L. Corey. 1996. Suppression of subclinical shedding of herpes simplex virus type 2 with acyclovir. Ann. Intern. Med. 124:8-15.

24. Elion, G.B., P.A. Furman, J.A. Fyfe, P.D. Miranda, L. Beauchamp, and H.J. Schaeffer. 1977. Selectivity of action of an antiherpetic agent, 9-(2-hydroxyethoxymethyl)-guanine. Proc. Natl. Acad. Sciences. USA. 74:5716-5720.

25. Ward, P.L., and B. Roizman. 1994. Herpes simplex genes: the blueprint of a successful human pathogen (published erratum appears in Trends Genet. 10:380). Trends Genet. 10:267-274.

26. Wagner, E.K., G. Devi-Rao, L.T. Feldman, A.T. Dobson, Y.F. Zhang,
W.H. Flanagan, and J.G. Stevens. 1988. Physical characterization of the herpes simplex virus latency-associated transcript in neurons. J. Virol. 62:1194-1202.

27. Stevens, J.G., L. Haar, and D.D. Porter. 1988. Prominence of the herpes simplex virus latency-associated transcript in trigeminal ganglia from seropositive humans. J. Infect. Dis. 158:117-123.

28. Langenberg, A., R. Zbanyszek, J. Dragavon, R. Ashley, and L. Corey. 1988. Comparison of diploid fibroblast and rabbit kidney tissue culture and diploid fibroblast microtiter plate system for the isolation of herpes simplex virus. J. Clin. Microbiol. 26:1772-1774.

29. Cone, R.W., A.C. Hobson, and M.L.W. Huang. 1992. Coamplified positive control detects inhibition of polymerase chain reactions. J. Clin. Microbiol. 30:3185-3189.

30. Hobson, A., A. Wald, N. Wright, and L. Corey. 1997. Evaluation of a quantitative competitive PCR assay for measuring HSV DNA in genital tract secretions. J. Clin. Microbiol. In press.

31. Hill, T.J., D.A. Harbour, and W.A. Blyth. 1980. Isolation of herpes simplex virus from the skin of clinically normal mice during latent infection. J. Gen. Virol. 1980-47:205-207.

32. Scriba, M. 1981. Persistence of herpes simplex virus infection in ganglia and peripheral tissues of guinea pigs. Med. Microbiol. Immunol. 169:91-96.

33. Rong, B.L., D. Pavan-Langston, Q.P. Weng, R. Martinez, J.M. Cherry, and E.C. Dunkel. 1991. Detection of herpes simplex virus thymidine kinase and latency-associated transcript gene sequences in human herpetic corneas by polymerase chain reaction amplification. Invest. Ophthalmol. Visual Sci. 32: 1808-1815. 